\title{
Efeitos do AEB conjugado e do Bionator no tratamento da Classe II, $1^{\text {a }}$ divisão*
}

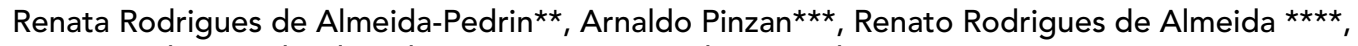

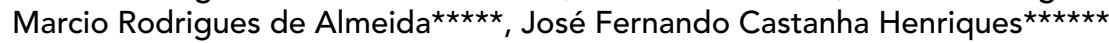

\begin{abstract}
Resumo
Este estudo cefalométrico objetivou avaliar as alterações dentárias e esqueléticas, em jovens com má oclusão de Classe II, $1^{a}$ divisão, tratados com o aparelho extrabucal conjugado (splint maxilar) e com o Bionator. Estes dois grupos experimentais foram comparados a um grupo de jovens portadores da mesma má oclusão que não receberam tratamento, pareados pelo gênero, idade, tempo de observação e grandezas cefalométricas iniciais. A amostra constou de 180 telerradiografias em norma lateral de 90 jovens, divididos em três grupos de 30, sendo 15 do gênero masculino e 15 do feminino. Os jovens do grupo 1 foram mantidos como controle e apresentaram uma idade inicial média de 10,02 anos e foram observados pelo período médio de 1,49 anos. O grupo 2 foi submetido ao tratamento utilizando o aparelho extrabucal conjugado (splint maxilar), com idade inicial média de 10,02 anos e tempo de observação de 1,78 anos. O grupo 3 foi tratado com o Bionator por um tempo médio de 1,52 anos e os jovens apresentavam idade inicial média de 10,35 anos. A análise dos resultados mostrou que o tratamento da má oclusão de Classe II, $1^{\text {a }}$ divisão com o AEB conjugado e com o Bionator resultou de efeitos específicos e inerentes a cada aparelho. Os resultados patentearam que o deslocamento anterior da maxila foi restringido significantemente pelo tratamento com o AEB conjugado. $\mathrm{O}$ Bionator promoveu um aumento significante na protrusão mandibular, enquanto que o AEB conjugado mostrou efeitos esqueléticos menos evidentes. No entanto, ambos aparelhos estudados produziram um aumento nos comprimentos efetivo e do corpo da mandíbula, com valores maiores para o grupo 2. A relação maxilomandibular melhorou significantemente nos grupos tratados em comparação ao grupo controle. A análise do padrão de crescimento craniofacial e das alturas faciais não revelou alteração significante entre os grupos. Em relação às alterações dentoalveolares ambos aparelhos provocaram inclinação para lingual e retrusão dos incisivos superiores, porém os efeitos do AEB conjugado foram significantemente mais intensos. Os incisivos inferiores foram afetados de maneira distinta pelos aparelhos. No grupo tratado com o AEB conjugado, os incisivos lingualizaram e retruíram enquanto que o grupo tratado com o Bionator apresentou inclinação para vestibular e protrusão destes dentes. Os molares inferiores apresentaram um maior desenvolvimento vertical e horizontal nos grupos 2 e 3. Os primeiros molares superiores distalizaram no grupo tratado com o AEB conjugado, enquanto nos grupos 3 (Bionator) e controle houve mesialização. Deste modo, verificou-se que ambos os protocolos de tratamento propiciaram alterações esqueléticas, dentárias e tegumentares, distintas e clinicamente relevantes para a correção da má oclusão de Classe II, $1^{\text {a }}$ divisão.
\end{abstract}

Palavras-chave: Aparelho extrabucal. Bionator. Classe II, $1^{\text {a }}$ divisão. Ortopedia.

* Resumo da Tese de Doutorado, apresentada à Faculdade de Odontologia de Bauru-USP, 2003.

** Especialista, Mestre e Doutora em Ortodontia pela Faculdade de Odontologia de Bauru-USP e Professora de Ortodontia ao nível de Graduação e Especialização da Faculdade de Odontologia de Lins da Universidade Metodista de Piracicaba.

*** Professor Associado do Departamento de Ortodontia e Odontopediatria da Faculdade de Odontologia de Bauru-USP, Titular da USC-Bauru e Orientador da pesquisa.

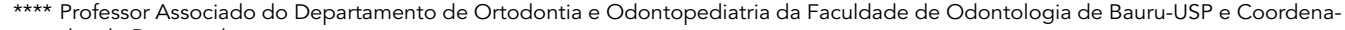
dor do Doutorado.

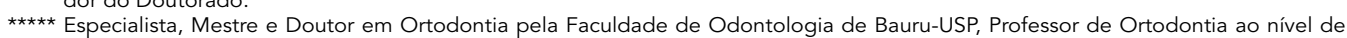
Graduação e Coordenador do Curso de Especialização da Faculdade de Odontologia de Lins da Universidade Metodista de Piracicaba.

****** Professor Titular do Departamento de Ortodontia e Odontopediatria da Faculdade de Odontologia de Bauru-USP. 


\section{INTRODUÇÃO}

A má oclusão de Classe II pode comprometer a harmonia facial em diversos graus, de acordo com a intensidade da sobressaliência (overjet) dentária e de sua interação com as estruturas adjacentes de tecidos moles, interferindo na imagem e autoestima do paciente ${ }^{46,65}$, assim o tratamento desta má oclusão é importante para a ressocialização do paciente e de grande interesse para os ortodontistas, sendo que a demanda pelo tratamento é significante na clínica ortodôntica uma vez que esta má oclusão tem o maior percentual nas clínicas ortodônticas de todo o mundo, alcançando índices de $55 \%{ }^{23}$.

O protocolo de tratamento da Classe II depende da idade do paciente, do comprometimento estético e oclusal. A interceptação da má oclusão de Classe II constitui um dos assuntos mais estudados e controversos da Ortodontia contemporânea, em função dos diferentes tipos de aparelhos disponíveis e da época ideal para o início do tratamento, destacando-se o tratamento em uma única fase (aparelhos fixos) e em duas fases (aparelhos ortopédicos e fixos). Os aparelhos ortopédicos visam corrigir a discrepância maxilo-mandibular nos sentidos ântero-posterior e transversal, contribuindo para uma melhora na relação das bases apicais, uma oclusão com estabilidade e harmonia do perfil facial. No entanto, o tratamento com aparelhos ortopédicos deve ser indicado para jovens em fase de crescimento e desenvolvimento craniofacial, com a finalidade de alterar espacialmente a forma e o posicionamento das bases ósseas, redirecionando o crescimento da maxila e liberando o da mandíbula, gerando uma nova situação mais estável e equilibrada.

Muitos estudos 1,2,3,17,18,25,35,50,51,65 compararam os efeitos de aparelhos ortopédicos funcionais como o Bionator, o Fränkel, o Herbst e os ativadores, na correção da má oclusão de Classe II, $1^{\text {a }}$ divisão. Porém há poucos trabalhos $20,41,46,67$ comparando as alterações promovidas por aparelhos ortopédicos mecânicos como o AEB (aparelho extrabucal) ou
AEB conjugado (splint maxilar) com aparelhos ortopédicos funcionais, gerando muita controvérsia em relação ao modo de ação destes aparelhos.

Há um consenso na literatura ${ }^{1,2,3,20,35,41,46,65,67}$ no que diz respeito à efetividade destes aparelhos na correção da má oclusão de Classe II, $1^{\text {a }}$ divisão, sendo que as alterações mais evidentes são o reposicionamento ântero-posterior das bases apicais, melhora da relação molar e redução da sobressaliência. Entretanto, existe uma polêmica em relação ao mecanismo de ação destes aparelhos no sentido ântero-posterior. O efeito mais evidente e de maior consenso entre os pesquisadores é a restrição do crescimento anterior da maxila pro-

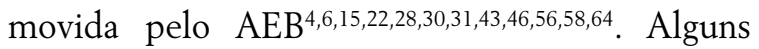
estudos $^{20,26,37,5354,57,59,60,66}$ indicam que os ativadores também inibem o deslocamento anterior do maxilar, mas todos concordam que o AEB é mais efetivo. O efeito destes aparelhos no posicionamento mandibular é um ponto mais controverso, sendo que muitos estudos 10,11,13,14,16,19,20,24,25,32,37, $38,41,44,46,48,49,52,55,57,59,62,63$ mostraram efeitos positivos na mandíbula com o uso de ativadores e até mesmo com o $\mathrm{AEB}^{9,22,28,29,31,41,43,46,56,64}$ e outras pesquisas $^{15,26,27,51,53,66}$ não verificaram influência destes aparelhos na base apical inferior, no entanto, a controvérsia ainda existe. E a questão polêmica permanece sem resposta definida. Será que os aparelhos ortopédicos, sejam eles mecânicos ou funcionais, produzem alterações significantes no crescimento mandibular?

Outra questão relevante envolve as alterações dentárias decorrentes da utilização destes aparelhos ortopédicos, principalmente no sentido vertical, pois poucos estudos randômicos avaliaram tais efeitos ${ }^{41}$. A distalização dos molares superiores com o uso do AEB é ponto pacífico entre os pesquisadores; o mesmo não se pode extrapolar para os aparelhos funcionais, ocorrendo muita discórdia. Por outro lado, existe uma dicotomia de opiniões referente ao posicionamento destes dentes no sentido vertical e em relação aos efeitos sobre os incisivos. 
Ainda hoje, a literatura ortodôntica mostrase controversa quanto aos efeitos esqueléticos e dentários decorrentes dos aparelhos ortopédicos. Conseqüentemente às alterações dento-esqueléticas, seriam os aparelhos ortopédicos capazes de melhorar significantemente o perfil facial do paciente?

Diante destas considerações o objetivo deste trabalho consistiu em analisar cefalometricamente as alterações nos componentes maxilar, mandibular e dentoalveolar, nas relações maxilo-mandibular e vertical de dois grupos de jovens com má oclusão de Classe II, $1^{\text {a }}$ divisão, tratados com o aparelho extrabucal conjugado e com o Bionator e comparar com um grupo de jovens portadores de má oclusão semelhante que não foram submetidos ao tratamento ortodôntico.

\section{MATERIAL E MÉTODOS}

A amostra constou de 180 telerradiografias em norma lateral, de 90 jovens brasileiros de ambos os gêneros provenientes do acervo da Disciplina de Ortodontia da Faculdade de Odontologia de Bauru, da Universidade de São Paulo e do arquivo particular do CORA - Centro Odontolólgico Rodrigues de Almeida. A amostra foi dividida em 3 grupos (Tab. 1):

- Grupo 1 (controle), constituído de 30 jovens, sendo 15 do gênero masculino e 15 do feminino que apresentavam má oclusão de Classe II, $1^{\text {a }}$ divisão, não submetidos a nenhum tipo de tratamento ortodôntico com idade inicial média de 10,02 anos, acompanhados por um período médio de

Tabela 1 - Média das idades iniciais e finais dos jovens nos 3 grupos e o tempo médio de avaliação.

\begin{tabular}{cccc}
\hline GRUPOS & $\begin{array}{c}\text { MÉDIA DE } \\
\text { IDADE INICIAL }\end{array}$ & $\begin{array}{c}\text { MÉDIA DE } \\
\text { IDADE FINAL }\end{array}$ & $\begin{array}{c}\text { TEMPO MÉDIO } \\
\text { DE AVALIA- } \\
\text { ÇÃ̃ }\end{array}$ \\
\hline 1 (controle) & $10,02 a$. & $11,51 a$. & $1,49 a$. \\
$\begin{array}{c}\text { (AEB conju- } \\
\text { gado) }\end{array}$ & $10,02 a$. & $11,80 a$. & $1,78 a$. \\
3 (Bionator) & $10,35 a$. & $11,87 a$. & $1,52 a$. \\
\hline
\end{tabular}

1,49 anos. Selecionou-se esta amostra a partir de um grupo de jovens que foi anualmente radiografado e controlado pela Disciplina de Ortodontia da FOB-USP com o fim de obter uma amostra longitudinal de oclusões jovens, desde a dentadura mista até a permanente.

- Grupo 2, submetido ao tratamento utilizando o aparelho extrabucal conjugado, apresentando 15 jovens do gênero masculino e 15 do feminino, com idade inicial média de 10,02 anos e acompanhados por um período médio de 1,78 anos. Todos os pacientes deste grupo foram tratados no CORA (Centro Odontológico Rodrigues de Almeida).

- Grupo 3, recebeu tratamento por meio do Bionator, constituindo-se de 15 jovens do gênero masculino e 15 do feminino, com idade inicial média de 10,35 anos e acompanhados por um período médio de 1,52 anos. Os pacientes foram tratados nos cursos de Pós-Graduação (mestrado e doutorado) da Faculdade de Odontologia de Bauru, Universidade de São Paulo.

\section{PROTOCOLO DE TRATAMENTO}

\section{Aparelho extrabucal conjugado}

O AEB conjugado é composto por uma placa de acrílico superior, com plano de levantamento oclusal e com parafuso expansor, arco vestibular, grampo de Adams, arco facial e casquete com tração alta. Para a retenção da placa são construídos grampos de Adams nos molares e um arco vestibular usado para a verticalização dos incisivos, se necessário, ou para prevenir a sua vestibularização.

O arco facial é incluído no acrílico, passando por distal dos primeiros molares decíduos ou entre os pré-molares. As extremidades do arco externo são dobradas na altura dos primeiros molares superiores ou ao nível do canto externo do olho, (aproximadamente $2 \mathrm{~cm}$ após o término da placa acrílica) onde são inseridos os elásticos que promovem uma força com ponto de aplicação mais próximo ao centro de resistência da maxila, 
ou seja, com inclinação de 45 graus acima do plano oclusal direcionada ao centro de resistência da maxila gerando força de compressão perpendicularmente às suturas primárias maxilares (Frontomaxilar, Zigomáticomaxilar e Pterigopalatina). $\mathrm{O}$ acrílico que recobre a face oclusal dos dentes posteriores deve ser delgado para não promover a translação condilar ou aumento da altura facial do paciente geralmente vertical. Neste gancho, são utilizados elásticos de $1 / 2$ polegada de diâmetro acoplados ao casquete com tração alta, permitindo uma restrição tanto do deslocamento anterior da maxila quanto da extrusão dos molares superiores, melhorando o relacionamento maxilo-mandibular, além de permitir a retenção do aparelho.

\section{Manipulação clínica do aparelho}

Os pacientes deveriam utilizar aparelho por 16 a 18 horas diárias com força entre 350 a $500 \mathrm{~g}$ e os elásticos de tração de $1 / 2$ polegada foram trocados pelo próprio paciente a cada dez dias. Procedeu-se a ativação mensal do parafuso expansor com $1 / 4$ volta/mês para melhor ajuste transversal da maxila com a mandíbula.

\section{Aparelho do tipo Bionator}

O aparelho utilizado apresentou, na sua constituição, quatro elementos básicos: uma base de acrílico, alças palatina e vestibular e dobras do bucinador, sendo que cada qual, dependendo do tipo de aparelho, apresenta características específicas de acordo com as diferentes finalidades terapêuticas. A parte ântero-inferior de acrílico recobre os incisivos inferiores, diminuindo a extrusão e protrusão dos mesmos ${ }^{39}$. A alça vestibular construída originalmente para guiar ou facilitar o vedamento labial, toca suavemente os incisivos superiores, funcionando como elemento ativo durante o tratamento ${ }^{46}$.

Os pacientes foram requisitados a utilizar o aparelho por no mínimo 18 a 20 horas diárias, excetuando-se o período de alimentação e prática de excercícios físicos.

\section{Radiografias cefalométricas}

Foram utilizadas duas telerradiografias, em norma lateral, de cada paciente, consideradas como Tl (inicial) e T2 (final). Uma atenção especial foi requerida no sentido de identificar uma eventual mordida protrusiva, ao início e no final das tomadas radiográficas. Os cefalogramas foram traçados manualmente sobre o negatoscópio, pelo pesquisador e conferido pelo orientador da investigação, em uma sala obscurecida, emoldurado com cartolina preta, expondo-se as áreas correspondentes ao desenho anatômico. Por meio de uma mesa digitalizadora Houston Instruments DT-11 (Houston Instruments - Austin, Texas, USA), acoplada a um microcomputador 586 Pentium, transferiuse a localização dos pontos dos cefalogramas para o programa de cefalometria Dentofacial Planner 7.0 (Dentofacial Planner Software Inc., Toronto, Ontario, Canada.) onde foram processadas as mensurações envolvendo os planos e as linhas. As grandezas angulares e lineares utilizadas no estudo encontram-se dispostas nas figuras 1, 2 e 3 .

\section{ANÁLISE ESTATÍSTICA}

\section{Erro do método}

Com o intuito de determinar a confiabilidade dos resultados da pesquisa, foram selecionadas ao acaso 20 telerradiografias provenientes dos 3 grupos estudados, que foram traçadas e digitalizadas novamente pelo mesmo pesquisador após um período de 1 mês, do traçado inicial. Determinou-se a diferença entre a primeira e a segunda mensuração de cada telerradiografia, e verificou-se o erro casual (fórmula de Dahlberg) e o erro sistemático (teste $t$ pareado).

\section{Equivalência entre as idades dos grupos}

As médias de idades dos pacientes no início e no final do tratamento, bem como a duração desse período, foram avaliadas por meio da análise de Variância ANOVA para verificar o grau de seme- 


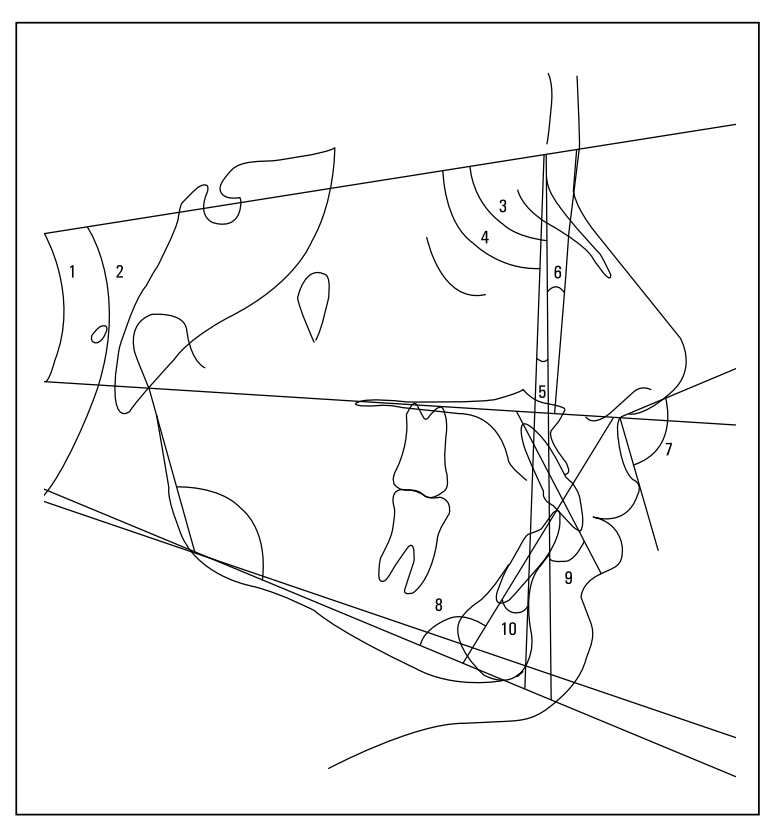

FIGURA 1 - Grandezas angulares.

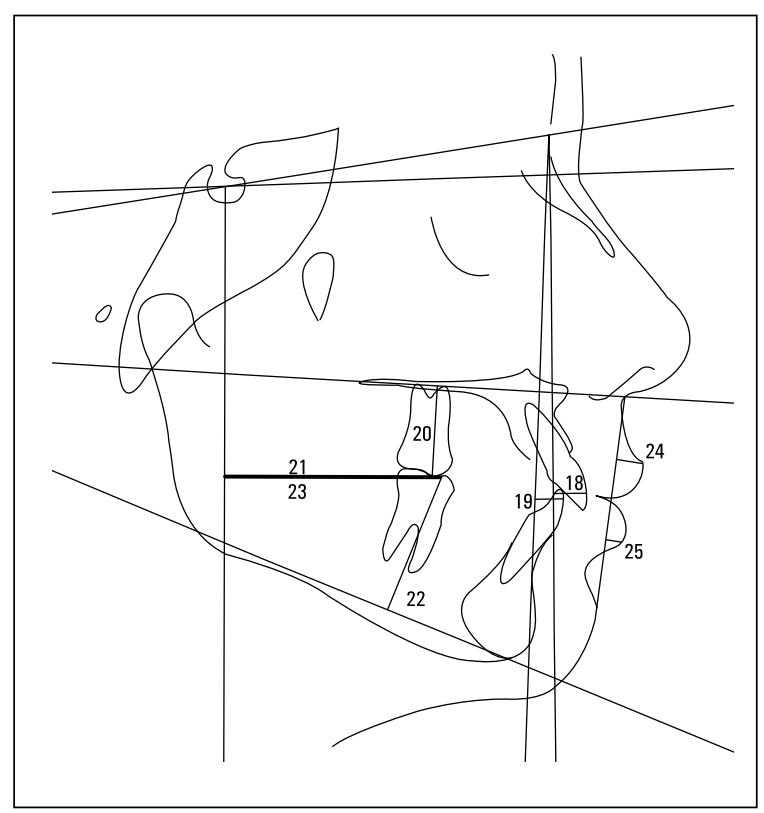

FIGURA 3 - Grandezas lineares dentárias.

lhança entre os grupos. A equivalência, principalmente, do período de avaliação dos grupos tratados e controle é importante, uma vez que propicia resultados mais confiáveis quando se compara os

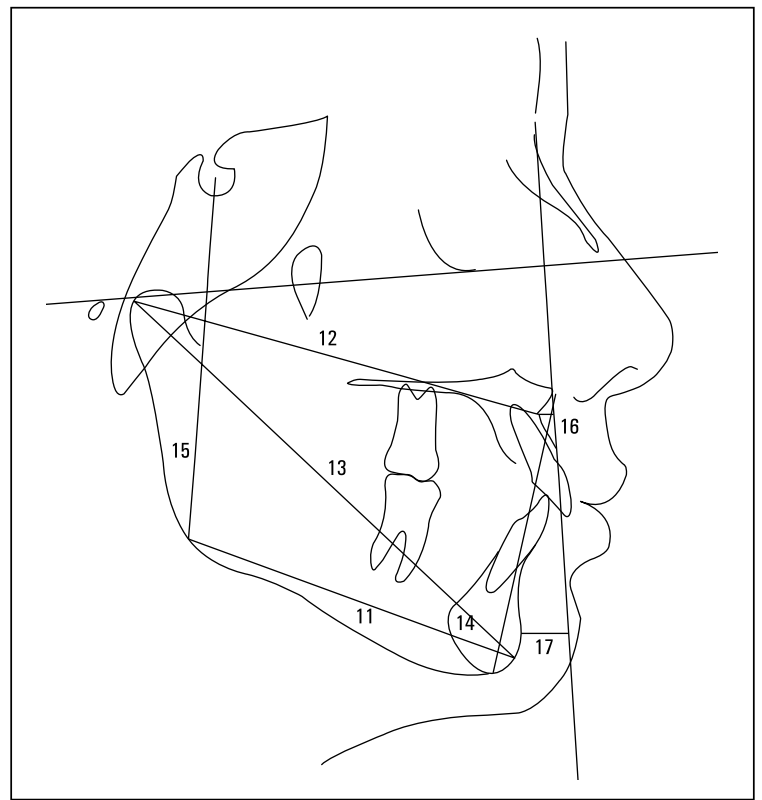

FIGURA 2 - Grandezas lineares esqueléticas.

Tabela 2 - Análise de Variância (ANOVA) entre as médias das idades iniciais e finais dos jovens nos 3 grupos e do tempo médio de avaliação.

\begin{tabular}{|c|c|c|c|c|c|c|}
\hline \multirow[t]{2}{*}{ VARIÁVEIS } & \multicolumn{3}{|c|}{ VALORES MÉDIOS } & \multicolumn{2}{|c|}{$\begin{array}{l}\text { ANÁLISE } \\
\text { DE } \\
\text { VARIÂN- } \\
\text { CIA }\end{array}$} & \multirow[t]{2}{*}{ SIG. } \\
\hline & $\begin{array}{c}\text { GRUPO } \\
1\end{array}$ & $\begin{array}{c}\text { GRUPO } \\
2\end{array}$ & $\begin{array}{c}\text { GRUPO } \\
3\end{array}$ & $\mathrm{~F}$ & $P$ & \\
\hline IDADE INICIAL & $10,02 \mathrm{a}$ & $10,02 \mathrm{a}$ & $10,35 a$ & 1,09 & 0,34 & $\mathrm{~N} / \mathrm{S}$ \\
\hline IDADE FINAL & 11,51a. & 11,80a. & 11,87a. & 0,98 & 0,37 & $\mathrm{~N} / \mathrm{S}$ \\
\hline $\begin{array}{c}\text { TEMPO DE } \\
\text { AVALIAÇÃAO }\end{array}$ & $1,49 a$ & $1,78 \mathrm{a}$ & $1,52 a$ & 2,21 & 0,11 & $\mathrm{~N} / \mathrm{S}$ \\
\hline
\end{tabular}

efeitos provenientes dos aparelhos com os efeitos do próprio crescimento e desenvolvimento craniofacial.

\section{Comparação entre os grupos}

Inicialmente realizou-se uma análise intergrupos das médias iniciais das grandezas cefalométricas de cada grupo, utilizando a análise de Variância (ANOVA), com o objetivo de verificar o grau de similaridade entre os grupos. 
Efeitos do AEB conjugado e do Bionator no tratamento da Classe II, $1^{\text {a }}$ divisão

Tabela 3 - Análise de Variância (ANOVA) entre os 3 grupos dos valores médios das medidas iniciais.

\begin{tabular}{|c|c|c|c|c|c|c|}
\hline \multirow{2}{*}{$\begin{array}{c}\text { GRANDEZAS } \\
\text { CEFALOMÉTRICAS }\end{array}$} & \multicolumn{3}{|c|}{ MÉDIAS DAS MEDIDAS INICIAIS } & \multicolumn{3}{|c|}{ SIGNIFICÂNCIA } \\
\hline & Controle & AEB conjugado & Bionator & C-AEB & C-B & AEB-B \\
\hline \multicolumn{7}{|l|}{ Maxilares } \\
\hline SNA & 80,44 & 81,37 & 81,45 & $\mathrm{~N} / \mathrm{S}$ & $\mathrm{N} / \mathrm{S}$ & $\mathrm{N} / \mathrm{S}$ \\
\hline Nperp-A & $-2,21$ & $-1,47$ & $-1,43$ & $\mathrm{~N} / \mathrm{S}$ & $\mathrm{N} / \mathrm{S}$ & $\mathrm{N} / \mathrm{S}$ \\
\hline Co-A & 81,02 & 78,83 & 82,28 & $\mathrm{~N} / \mathrm{S}$ & $\mathrm{N} / \mathrm{S}$ & Sig ** \\
\hline \multicolumn{7}{|l|}{ Mandibulares } \\
\hline SNB & 75,36 & 75,19 & 75,48 & $\mathrm{~N} / \mathrm{S}$ & $\mathrm{N} / \mathrm{S}$ & $\mathrm{N} / \mathrm{S}$ \\
\hline Nperp-P & $-10,68$ & $-11,23$ & $-11,05$ & $\mathrm{~N} / \mathrm{S}$ & $\mathrm{N} / \mathrm{S}$ & $\mathrm{N} / \mathrm{S}$ \\
\hline Go-Gn & 65,56 & 64,49 & 66,73 & $\mathrm{~N} / \mathrm{S}$ & $\mathrm{N} / \mathrm{S}$ & $\mathrm{N} / \mathrm{S}$ \\
\hline Co-Gn & 99,25 & 96,96 & 100,31 & $\mathrm{~N} / \mathrm{S}$ & $\mathrm{N} / \mathrm{S}$ & Sig ** \\
\hline \multicolumn{7}{|l|}{ Maxilomandibulares } \\
\hline ANB & 5,07 & 6,18 & 5,96 & $\mathrm{~N} / \mathrm{S}$ & $\mathrm{N} / \mathrm{S}$ & $\mathrm{N} / \mathrm{S}$ \\
\hline NAP & 8,63 & 10,84 & 10,54 & $\mathrm{~N} / \mathrm{S}$ & $\mathrm{N} / \mathrm{S}$ & $\mathrm{N} / \mathrm{S}$ \\
\hline \multicolumn{7}{|l|}{ Verticais } \\
\hline SN.GoGn & 32,36 & 34,48 & 33,25 & $\mathrm{~N} / \mathrm{S}$ & $\mathrm{N} / \mathrm{S}$ & $\mathrm{N} / \mathrm{S}$ \\
\hline SN.PP & 7,67 & 7,62 & 7,61 & $\mathrm{~N} / \mathrm{S}$ & $\mathrm{N} / \mathrm{S}$ & $\mathrm{N} / \mathrm{S}$ \\
\hline AFAI & 58,76 & 58,77 & 59,88 & $\mathrm{~N} / \mathrm{S}$ & $\mathrm{N} / \mathrm{S}$ & $\mathrm{N} / \mathrm{S}$ \\
\hline S-Go & 64,19 & 61,15 & 64,73 & Sig ** & $\mathrm{N} / \mathrm{S}$ & Sig ** \\
\hline \multicolumn{7}{|l|}{$\begin{array}{l}\text { Dentárias } \\
\text { superiores }\end{array}$} \\
\hline 1.NA & 24,89 & 27,89 & 26,22 & $\mathrm{~N} / \mathrm{S}$ & $\mathrm{N} / \mathrm{S}$ & $\mathrm{N} / \mathrm{S}$ \\
\hline 1-NA & 4,73 & 5,57 & 5,54 & $\mathrm{~N} / \mathrm{S}$ & $\mathrm{N} / \mathrm{S}$ & $\mathrm{N} / \mathrm{S}$ \\
\hline$\underline{6}-\mathrm{FHp}$ & 32,86 & 32,06 & 34,07 & $\mathrm{~N} / \mathrm{S}$ & $\mathrm{N} / \mathrm{S}$ & $\mathrm{N} / \mathrm{S}$ \\
\hline$\underline{6}-\mathrm{PP}$ & 18,26 & 18,27 & 19,19 & $\mathrm{~N} / \mathrm{S}$ & $\mathrm{N} / \mathrm{S}$ & $\mathrm{N} / \mathrm{S}$ \\
\hline \multicolumn{7}{|l|}{$\begin{array}{l}\text { Dentárias } \\
\text { inferiores }\end{array}$} \\
\hline$\overline{1} . \mathrm{NB}$ & 24,82 & 27,09 & 26,42 & $\mathrm{~N} / \mathrm{S}$ & $\mathrm{N} / \mathrm{S}$ & $\mathrm{N} / \mathrm{S}$ \\
\hline$\overline{1}-N B$ & 4,42 & 4,88 & 5,20 & $\mathrm{~N} / \mathrm{S}$ & $\mathrm{N} / \mathrm{S}$ & $\mathrm{N} / \mathrm{S}$ \\
\hline$\overline{6}-\mathrm{FHp}$ & 32,90 & 31,76 & 33,91 & $\mathrm{~N} / \mathrm{S}$ & $\mathrm{N} / \mathrm{S}$ & $\mathrm{N} / \mathrm{S}$ \\
\hline$\overline{6}$-GoMe & 26,05 & 25,33 & 26,24 & $\mathrm{~N} / \mathrm{S}$ & $\mathrm{N} / \mathrm{S}$ & $\mathrm{N} / \mathrm{S}$ \\
\hline IMPA & 94,72 & 94,84 & 95,38 & $\mathrm{~N} / \mathrm{S}$ & $\mathrm{N} / \mathrm{S}$ & $\mathrm{N} / \mathrm{S}$ \\
\hline
\end{tabular}

$\mathrm{N} / \mathrm{S}=$ não significante, Sig. ${ }^{*}=$ significante $(p \leq 0,05)$, Sig. ${ }^{* *}=$ significante $(p \leq 0,01)$.

As diferenças entre as mensurações nas fases pré e pós-tratamento determinaram as alterações reais. Para verificação das alterações ocorridas nos três grupos foram calculadas as diferenças entre as medidas inicial e final, utilizando a fórmula:

$$
\text { valor final }- \text { valor inicial }=\text { diferença }
$$

Os dados obtidos nas medidas cefalométricas (diferenças das médias das alterações) para os três grupos foram computados pela análise de variância (ANOVA) para a verificação da hipótese nula de que os efeitos do crescimento no grupo 1, ou do tratamento nos grupos 2 e 3 são iguais. Quando verificadas diferenças estatísticas entre os grupos, 
Tabela 4 - Análise de Variância (ANOVA) entre os 3 grupos das diferenças das médias das alterações iniciais e finais.

\begin{tabular}{|c|c|c|c|c|c|c|}
\hline \multirow{2}{*}{$\begin{array}{c}\text { GRANDEZAS } \\
\text { CEFALOMÉTRICAS }\end{array}$} & \multicolumn{3}{|c|}{ DIFERENÇA DAS MÉDIAS DAS ALTERAÇÕES } & \multicolumn{3}{|c|}{ SIGNIFICÂNCIA } \\
\hline & Controle & AEB conjugado & Bionator & C-AEB & C-B & AEB-B \\
\hline \multicolumn{7}{|l|}{ Maxilares } \\
\hline SNA & $-0,49$ & $-1,48$ & $-0,34$ & Sig.** & $\mathrm{N} / \mathrm{S}$ & Sig. ${ }^{* *}$ \\
\hline Nperp-A & $-0,77$ & $-1,38$ & $-0,35$ & $\mathrm{~N} / \mathrm{S}$ & $\mathrm{N} / \mathrm{S}$ & Sig. ${ }^{* *}$ \\
\hline Co-A & 2,33 & 1,72 & 0,81 & $\mathrm{~N} / \mathrm{S}$ & Sig. ${ }^{*}$ & $\mathrm{~N} / \mathrm{S}$ \\
\hline \multicolumn{7}{|l|}{ Mandibulares } \\
\hline SNB & $-0,18$ & 0,46 & 1,23 & $\mathrm{~N} / \mathrm{S}$ & Sig.** & Sig.* \\
\hline Nperp-P & $-0,83$ & 0,44 & 1,23 & $\mathrm{~N} / \mathrm{S}$ & Sig.** & $\mathrm{N} / \mathrm{S}$ \\
\hline Go-Gn & 2,57 & 3,35 & 2,33 & $\mathrm{~N} / \mathrm{S}$ & $\mathrm{N} / \mathrm{S}$ & $\mathrm{N} / \mathrm{S}$ \\
\hline Co-Gn & 3,23 & 5,29 & 4,15 & $\mathrm{~N} / \mathrm{S}$ & $\mathrm{N} / \mathrm{S}$ & $\mathrm{N} / \mathrm{S}$ \\
\hline \multicolumn{7}{|l|}{ Maxilomandibulares } \\
\hline ANB & $-0,45$ & $-1,95$ & $-1,55$ & Sig.** & Sig.** & $\mathrm{N} / \mathrm{S}$ \\
\hline NAP & $-0,86$ & $-4,42$ & $-2,90$ & Sig.** & Sig.** & $\mathrm{N} / \mathrm{S}$ \\
\hline \multicolumn{7}{|l|}{ Verticais } \\
\hline SN.GoGn & $-0,36$ & $-0,19$ & 0,22 & $\mathrm{~N} / \mathrm{S}$ & $\mathrm{N} / \mathrm{S}$ & $\mathrm{N} / \mathrm{S}$ \\
\hline SN.PP & 0,77 & 0,89 & 0,44 & $\mathrm{~N} / \mathrm{S}$ & $\mathrm{N} / \mathrm{S}$ & $\mathrm{N} / \mathrm{S}$ \\
\hline AFAl & 1,45 & 2,38 & 2,59 & $\mathrm{~N} / \mathrm{S}$ & $\mathrm{N} / \mathrm{S}$ & $\mathrm{N} / \mathrm{S}$ \\
\hline S-Go & 2,76 & 3,66 & 3,70 & $\mathrm{~N} / \mathrm{S}$ & $\mathrm{N} / \mathrm{S}$ & $\mathrm{N} / \mathrm{S}$ \\
\hline \multicolumn{7}{|l|}{$\begin{array}{l}\text { Dentárias } \\
\text { superiores }\end{array}$} \\
\hline 1.NA & 0,68 & $-9,26$ & $-4,48$ & Sig. ${ }^{* *}$ & Sig.** & Sig. ${ }^{* *}$ \\
\hline 1-NA & 0,48 & $-1,77$ & $-0,69$ & Sig. ${ }^{* *}$ & Sig.* & Sig.* \\
\hline$\underline{6}-\mathrm{FHp}$ & 0,92 & $-1,27$ & 0,10 & Sig.* & $\mathrm{N} / \mathrm{S}$ & $\mathrm{N} / \mathrm{S}$ \\
\hline$\underline{6}-\mathrm{PP}$ & 1,19 & 0,69 & 0,88 & $\mathrm{~N} / \mathrm{S}$ & $\mathrm{N} / \mathrm{S}$ & $\mathrm{N} / \mathrm{S}$ \\
\hline \multicolumn{7}{|l|}{$\begin{array}{l}\text { Dentárias } \\
\text { inferiores }\end{array}$} \\
\hline 1.NB & 0,33 & $-2,22$ & 4,25 & Sig.* & Sig.** & Sig. ${ }^{* *}$ \\
\hline$\overline{1}-N B$ & 0,24 & $-0,22$ & 1,12 & $\mathrm{~N} / \mathrm{S}$ & Sig.** & Sig. ${ }^{* *}$ \\
\hline$\overline{6}-\mathrm{FHp}$ & 1,05 & 2,69 & 3,27 & Sig.** & Sig.** & $\mathrm{N} / \mathrm{S}$ \\
\hline$\overline{6}$-GoMe & 0,79 & 1,78 & 1,55 & Sig. ${ }^{* *}$ & Sig. ${ }^{*}$ & $\mathrm{~N} / \mathrm{S}$ \\
\hline IMPA & 1,00 & $-2,48$ & 2,79 & Sig. ${ }^{* *}$ & $\mathrm{~N} / \mathrm{S}$ & Sig. ${ }^{* *}$ \\
\hline
\end{tabular}

$\mathrm{N} / \mathrm{S}=$ não significante, Sig. ${ }^{*}=$ significante $(p \leq 0,05)$, Sig. ${ }^{* *}=$ significante $(p \leq 0,01)$.

os valores das alterações das médias foram submetidos ao teste estatístico de Tukey, com a finalidade de identificar quais foram responsáveis pela rejeição da hipótese nula, de igualdade entre os grupos. Em todas as análises empregadas foram considerados estatisticamente significantes os resultados com valor de $p \leq 0,05$ e $p \leq 0,01$.

\section{RESULTADOS}

\section{Erro do método}

Evidenciou-se que apenas uma variável ( $\overline{6}$ - GoMe) das 22 apresentou um erro sistemático elucidado pelo resultado do teste estatístico $t$ de Student ao nível de significância de 5\%. No entanto, 
os erros provenientes de medidas dentárias estão previstos no envelope de erros sugerido por Baumrid e Frantz. ${ }^{12}$ Avaliando-se o erro casual do método, não se observou um valor maior que 0,93 para as medidas angulares ou 1,00 para as medidas lineares, demonstrando que a demarcação ou localização dos pontos não interferiu na obtenção das grandezas cefalométricas. Portanto, pode-se considerar que os resultados do erro metodológico demonstraram uma reprodutibilidade adequada dos cefalogramas realizados pelo examinador, uma vez que a precisão das mensurações empregadas nesta pesquisa encontrouse dentro dos parâmetros aceitáveis não comprometendo os resultados e conclusões deste estudo.

\section{Equivalência entre as idades dos grupos}

Os resultados mostraram um grau de compatibilidade muito grande entre as idades iniciais, finais e tempo de avaliação entre os grupos, tornando possivel a comparação direta entre elas (Tab. 2).

\section{Comparação intergrupos das medidas iniciais pela análise de variância - ANOVA (Tab. 3)}

Na tabela 3 observa-se o resultado da análise de variância (ANOVA) na comparação intergrupos, na fase pré-tratamento, para determinar o grau de similaridade entre os três grupos estudados, quanto aos seus valores cefalométricos iniciais.

Os resultados foram dispostos de uma forma geral na tabela 4, onde a comparação intergrupos foi verificada pela análise de variância (ANOVA) e complementada pelo teste de Tukey.

\section{DISCUSSÃO}

\section{Efeitos esqueléticos maxilares}

Os aparelhos avaliados nesta pesquisa, principalmente o AEB conjugado, surtiram efeitos sobre a posição espacial da maxila (referenciada pelo ponto A). Os resultados obtidos demonstraram diferenças estatísticas significantes entre os grupos. O ângulo SNA e a medida linear NperpA que definem a posição da maxila em relação à base do crânio diminuíram nos três grupos estudados, sendo esta diminuição maior no grupo tratado com o AEB conjugado $\left(-1,48^{\circ}\right.$ e $\left.-1,38 \mathrm{~mm}\right)$ com diferença significante. $\mathrm{O}$ grupo tratado com o Bionator $\left(-0,34^{\circ}\right.$ e $\left.-0.35 \mathrm{~mm}\right)$ mostrou-se semelhante ao grupo controle $\left(-0,49^{\circ}\right.$ e $\left.-0,77 \mathrm{~mm}\right)$ apresentando uma diminuição mais discreta destas medidas. Sendo assim, verificou-se que o AEB conjugado restringiu o desenvolvimento maxilar no sentido ântero-posterior concordando com os relatos de Almeida et al. ${ }^{4,6}$; Bass ${ }^{9}$; Caldwell, Hymas, Timm ${ }^{15}$; Fotis et al. ${ }^{22}$; Henriques ${ }^{28}$; Henriques et al. ${ }^{30,31}$; Maltagliati ${ }^{43}$; Martins ${ }^{46}$; Seçkin, Surucu ${ }^{56}$; Thurow $^{58}$; Üner, Eroglu ${ }^{64}$. Em relação ao Bionator verificou-se um comportamento muito semelhante ao do grupo controle demonstrando que a interceptação com este aparelho não promove efeitos restritivos sobre o desenvolvimento da maxila no sentido sagital. Resultados similares foram relatados pela maioria dos autores pesquisados ${ }^{1,2,5}$, $14,16,18,25,27,32,38,41,46,49,62,63,68$, que não encontraram influência do Bionator sobre o desenvolvimento maxilar. Por outro lado, na literatura alguns autores ${ }^{20,26,37,53,57,59,60,66}$ demonstraram que o Bionator promoveu uma restrição do crescimento para anterior da maxila, apontada pela diminuição do ângulo SNA.

Em relação ao comprimento efetivo da maxila, avaliada pela medida linear Co-A notou-se um aumento para todos os grupos, com diferença estatisticamente significante somente entre os grupos 1 $(2,33 \mathrm{~mm})$ e $3(0,81 \mathrm{~mm})$ (Tab. 4$)$. Deve-se destacar que esta medida é influenciada pelo avanço do ponto condílio devido ao deslocamento anterior da mandíbula em conseqüência do avanço mandibular alusivo ao mecanismo de ação do Bionator, assim, o efeito restritivo sobre a maxila é considerado uma interpretação inadequada. Em suma, os resultados desta pesquisa demonstraram que os aparelhos estudados apresentaram efeitos distintos sobre a maxila. Pode-se afirmar que o AEB conjugado promoveu uma restrição no desenvolvimento ântero-posterior da maxila enquanto que o 
Bionator não influenciou significantemente o posicionamento espacial desta base óssea.

\section{Efeitos esqueléticos mandibulares}

Neste estudo avaliou-se o posicionamento mandibular em relação à base do crânio pelas grandezas cefalométricas SNB e Nperp-P. O comprimento efetivo da mandíbula (Co-Gn) e o comprimento do corpo mandibular (Go-Gn) também foram analisados. Os resultados mostraram que as medidas SNB e Nperp-P aumentaram apenas nos grupos tratados, sendo que os valores foram maiores no grupo 3 , tratado com o Bionator $\left(1,23^{\circ}\right.$ e $\left.1,23 \mathrm{~mm}\right)$ apresentando diferença estatisticamente significante em relação ao grupo controle $\left(-0,18^{\circ}\right.$ e $\left.-0,83\right)$ e ao grupo $2\left(0,46^{\circ}\right.$ e $\left.0,44 \mathrm{~mm}\right)$. Corroborando com os resultados obtidos, Bass ${ }^{10,11}$; Bishara, Ziaja ${ }^{13}$; Bolmgren, Moshiri ${ }^{14}$; Chang et al. ${ }^{16}$; De Vincenzo ${ }^{19}$; Derringer ${ }^{20}$; Freunthaller ${ }^{24}$; Ghafari, King, Tulloch ${ }^{25}$; Henriques et al..$^{32}$; Jakobsson, Paulin ${ }^{37}$; Janson ${ }^{38}$; Keeling ${ }^{41}$; Lange $^{42}$; Mamandras, Allen ${ }^{44}$; Martins ${ }^{46}$; Meach ${ }^{48}$; Mills ${ }^{49}$; Op Heij et al. ${ }^{52}$; Schulhof, Enge1 ${ }^{55}$; Thüer, Ingervall, Bürgin $^{57}$; Tsamtsouris, Vedrenne ${ }^{59}$; Tulloch, Phillips, Proffit ${ }^{62}$ e Tulloch et al. ${ }^{63}$ demonstraram que o ângulo SNB aumentou com a utilização do Bionator. Discordando dos resultados da presente pesquisa, Harvold, Vargervik ${ }^{26}$; Hashim ${ }^{27}$; Nelson, Harkness, Herbison $^{51}$; Pancherz ${ }^{53}$; Vargervik e Harvold ${ }^{66}$ não evidenciaram um incremento mandibular resultante do tratamento com o Bionator de Balters. O grupo tratado com o AEB conjugado também apresentou um discreto aumento na protrusão mandibular enquanto o grupo controle mostrou uma diminuição do valor de SNB e Nperp-P sugerindo retrusão da mandíbula, no entanto este comportamento distinto entre os grupos não alcançou diferença estatisticamente significante. Com exceção de Caldwell, Hymas e Timm ${ }^{15}$, que verificaram uma diminuição do ângulo SNB, os resultados de todos os outros pesquisadores ${ }^{9,22,28,29,31,41,43,46,56,64}$ que avaliaram os efeitos do AEB conjugado corroboraram com os desta investigação. Contrarian- do os resultados desta pesquisa, diversos autores ${ }^{1,5,14,15,16,25,42,43,46,65}$ verificaram um aumento no valor de SNB nos pacientes com má oclusão de Classe II, $1^{\text {a }}$ divisão, não tratados.

As dimensões mandibulares representadas pelas medidas lineares Co-Gn e Go-Gn aumentaram nos três grupos, revelando-se sensivelmente maiores no grupo tratado com o AEB conjugado $(5,29 \mathrm{~mm}$ e $3,35 \mathrm{~mm}$ ), porém sem denotar uma diferença estatisticamente significante. Discordando dos resultados deste estudo Almeida ${ }^{1}$; Almeida et al. ${ }^{2,3,4}$; Derringer ${ }^{20}$; Faltin Junior et al. ${ }^{21}$; Schulhof e Engel ${ }^{55}$ observaram diferença significante no aumento do comprimento do corpo mandibular, avaliando pacientes com Classe II, tratados com o Bionator comparados a um grupo controle. $\mathrm{O}$ aumento do comprimento efetivo da mandíbula (Co-Gn) parece ser uma unanimidade entre os autores pesquisados $1,2,10,11,14,16,19,20,24,25,32,37,38,41,42,44,49,55,62,63,67$, embora nem todos, inclusive este estudo, tenham observado uma diferença significante entre os grupos tratados e os grupos controle 17,26,27,43,53. Embora as alterações ocorridas no comprimento efetivo da mandíbula não demonstrem diferença estatística, os resultados podem ser considerados clinicamente significantes, uma vez que os grupos tratados exibiram um aumento da taxa de crescimento mandibular de pelo menos 30\% em relação ao grupo controle. Um resultado surpreendente foi o maior aumento do comprimento total e do corpo mandibular no grupo tratado com o AEB conjugado $(5,29 \mathrm{~mm}$ e $3,35 \mathrm{~mm})$, em comparação com o aparelho Bionator $(4,15 \mathrm{~mm}$ e $2,33 \mathrm{~mm})$. Em relação ao grupo controle $(3,23 \mathrm{~mm}$ e $2,57 \mathrm{~mm}$ ), os valores indicaram uma taxa de crescimento do comprimento efetivo da mandíbula e do corpo nos casos tratados com AEB conjugado cerca de $70 \%$ e de $30 \%$ maiores, respectivamente. Estes resultados se respaldam na assertiva de You et al. ${ }^{69}$ que consideram fundamental para o tratamento da má oclusão de Classe II, $1^{\text {a }}$ divisão, a desoclusão dos dentes, liberando o crescimento mandibular. O estudo de Keeling et al. ${ }^{41}$ também 
está de acordo, confirmando que o tratamento da má oclusão de Classe II, $1^{\text {a }}$ divisão, com o AEB com placa de mordida (levantamento oclusal) produz um deslocamento significante da mandíbula para anterior, no entanto os autores afirmaram que a relação entre o uso da placa de levantamento oclusal com o maior crescimento mandibular ainda não está esclarecida. Parece-nos evidente que o AEB conjugado influencia positivamente o crescimento da mandíbula porém não foi possível com este estudo demonstrar estatisticamente este efeito. No entanto, cabe ressaltar mais uma vez que clinicamente os resultados podem ser significantes.

\section{Efeitos esqueléticos maxilo-mandibulares}

Em conseqüência às alterações ocorridas nos componentes maxilar e mandibular, a relação sagital entre as bases ósseas e a convexidade facial melhorou significantemente nos grupos tratados. Como era de se esperar, os ângulos ANB e NAP diminuíram significantemente nos grupos experimentais, possibilitando uma melhora no relacionamento maxilo-mandibular e na convexidade facial. Comparando-se os grupos tratados não foi verificada diferença estatística, embora o grupo 2 $\left(-1,95^{\circ}\right.$ e $\left.-4,42^{\circ}\right)$ tenha apresentado uma diminuição destes ângulos sensivelmente maior que o grupo tratado com o Bionator $\left(-1,55^{\circ}\right.$ e $\left.-2,90^{\circ}\right)$. No entanto, quando da comparação dos grupos experimentais com o grupo controle, observouse uma diferença estatisticamente significante, uma vez que os ângulos ANB e NAP diminuíram com maior intensidade nos grupos 2 e 3 e menos expressivamente no grupo $1\left(-0,45^{\circ}\right.$ e $\left.-0,86^{\circ}\right)$. Este resultado é substanciado na literatura por diversos autores ${ }^{1,2,5,16,20,32,37,42,49,53,57,62,63,68}$, que verificaram com o uso do Bionator uma melhora significante no grau de discrepância maxilo-mandibular e no ângulo de convexidade esquelética. Em relação ao AEB conjugado, a literatura corrobora com os resultados desta pesquisa $4,6,9,15,20,22,28,30,43,46,56,64$. Deve-se salientar que os aparelhos afetaram a relação maxilo-mandibular de maneira um pouco distinta. O AEB conjugado promoveu alterações mais expressivas no componente maxilar e o Bionator produziu efeitos quase que exclusivamente na mandíbula.

\section{Efeitos sobre a dimensão vertical}

Uma das características mais marcante da má oclusão de Classe II, $1^{\text {a }}$ divisão, é o comportamento das bases ósseas no sentido vertical. Comumente nesta má oclusão observa-se um excesso vertical de maxila, uma rotação horária da mandíbula e concomitantemente um aumento da $\mathrm{AFAI}^{33,47}$. Esta morfologia agrava a discrepância ântero-posterior. Assim, torna-se imprescindível o conhecimento dos efeitos suscitados por distintos aparelhos na correção desta entidade, buscando um controle vertical. As medidas angulares (SN.GoGn e SN.PP) que avaliam a inclinação dos planos mandibular e palatino em relação à base do crânio, não demonstraram alteração significante entre os grupos. No entanto, no grupo 1 $\left(-0.36^{\circ}\right)$ e $2\left(-0,19^{\circ}\right)$ verificou-se uma tendência ao fechamento do ângulo do plano mandibular, enquanto que no grupo $3\left(0,22^{\circ}\right)$ ocorreu um discreto aumento. Pode-se considerar que o uso do AEB conjugado, diferentemente dos efeitos decorrentes do uso isolado do AEB (cervical), controlou o crescimento da face no sentido vertical. Isto sugere que, mesmo diante de uma má oclusão de Classe II, $1^{\text {a }}$ divisão, com um padrão de crescimento desfavorável (vertical), pode-se utilizar este aparelho esperando resultados satisfatórios. Estes resultados estão de acordo com diversos pesquisadores ${ }^{1,3,15,28,29,30,37,42,45,46,64}$ que afirmaram que os aparelhos ortopédicos não influenciam o padrão de crescimento craniofacial. Em contrapartida, outros estudos demonstraram alterações do padrão de crescimento decorrentes da abordagem ortopédica $14,16,18,20,48,51,55,68$.

A AFAI e a medida S-Go possibilitaram a verificação das alterações no sentido vertical da face, onde se notou um comportamento uniforme no aumento destas grandezas nos três grupos, 
sem denotar diferença estatística. O grupo tratado com o Bionator $(2,59 \mathrm{~mm}$ e $3,70 \mathrm{~mm})$ apresentou um maior aumento destas medidas, seguido do grupo $2(2,38 \mathrm{~mm}$ e $3,66 \mathrm{~mm})$ e do grupo controle $(1,45 \mathrm{~mm}$ e $2,76 \mathrm{~mm})$ que apresentou menores valores, porém não diferente estatisticamente dos grupos experimentais. Estes resultados contrariam muitos estudos que demonstraram um aumento significante da $\mathrm{AFAI}^{14,15,16,18,20,32,35,3}$ $7,42,46,49,51,59,65,66,68$ e da altura facial posterior ${ }^{1,42}$ nos pacientes que utilizaram aparelhos ortopédicos em relação a grupos de pacientes não tratados. E concordam com outras pesquisas, que embora tenham observado um aumento da AFAI 1,28,30 não notaram diferença significante entre grupos tratados e controle. No entanto, como característica da má oclusão de Classe II, $1^{\text {a }}$ divisão, esperava-se um aumento de todas as grandezas cefalométricas avaliadas para o componente vertical. Concluindo, os resultados demonstraram que a interceptação desta má oclusão com o AEB conjugado e com o Bionator não alteraram o padrão de crescimento e não aumentaram demasiadamente as alturas faciais. Assim, pode-se inferir que os aparelhos mencionados apresentaram bons efeitos no sentido vertical, principalmente em relação ao AEB conjugado que apresentou um controle vertical sobre o plano mandibular.

\section{Efeitos dentoalveolares}

Os resultados desta pesquisa evidenciaram que os aparelhos avaliados promoveram alterações significantes no posicionamento dos incisivos superiores (1.NA e 1-NA). O comportamento deste dentes mostrou-se distinto em relação aos grupos experimentais e controle. Enquanto o grupo 1 (controle) experimentou uma vestibularização e protrusão dos incisivos superiores $\left(0,68^{\circ}\right.$ e $\left.0,48 \mathrm{~mm}\right)$, os grupos tratados mostraram a efetividade do tratamento com os incisivos inclinados para lingual e retruídos na base óssea após a intervenção. Esta diferença entre os grupos alcançou significância estatística. Entretanto, no grupo 2 (AEB conjugado) observou-se uma maior lingualização e retrusão dos incisivos $\left(-9,26^{\circ}\right.$ e $\left.-1,77 \mathrm{~mm}\right)$ comparado ao grupo $3\left(-4,48^{\circ}\right.$ e $-0,69 \mathrm{~mm}$ ), com diferença estatisticamente significante. Assegura-se, deste modo, que os aparelhos responderam de forma similar porém com intensidade diferente quanto à inclinação para lingual e retrusão dos incisivos superiores. Compulsando a literatura em relação ao AEB conjugado, quase todos os pesquisadores como Almeida et al. ${ }^{4,6}$; Caldwell, Hymas, Timm ${ }^{15}$; Fotis et al. ${ }^{22}$; Henriques ${ }^{28}$; Henriques et al. ${ }^{30}$; Joffe, Jacobson ${ }^{40}$; Maltagliati ${ }^{43}$ e Martins ${ }^{46}$ evidenciaram uma inclinação para lingual e retrusão dos incisivos superiores. Apenas Henriques et al. ${ }^{31}$; Thurow ${ }^{58}$; Üner e Eroglu ${ }^{64}$ não obtiveram os mesmos efeitos com o AEB conjugado. De acordo com os resultados desta investigação, vários estudos $3,5,10,11,13,14,16,18,32,38,49,53,57,59,66,68$ também concluíram que o ativador/Bionator atua efetivamente na correção da má oclusão de Classe II, $1^{\text {a }}$ divisão, retruindo e inclinando os incisivos superiores para lingual.

A divergência dos resultados em relação à intensidade da inclinação para lingual e retrusão dos incisivos superiores, observada entre os grupos tratados, ocorre em função do arco vestibular do AEB conjugado tocar ativamente a superfície vestibular destes dentes, enquanto no Bionator este arco geralmente não toca ou toca suavemente estes dentes. No entanto, a verticalização dos incisivos superiores pode ser altamente favorável nos casos de um trespasse horizontal acentuado com os incisivos inclinados para vestibular, características estas, freqüentemente observada na má oclusão de Classe II, $1^{\text {a }}$ divisão ${ }^{13}$. Por outro lado, uma lingualização excessiva destes dentes pode limitar o deslocamento anterior da mandíbula.

$\mathrm{O}$ posicionamento dos primeiros molares superiores no sentido vertical aferido pela medida 6-PP demonstrou similaridade nos três grupos $(1,19 \mathrm{~mm} ; 0,69 \mathrm{~mm}$ e $0,88 \mathrm{~mm})$, não obstante ocorreu um menor aumento nos grupos tratados, sem diferença estatística significante. Este efeito é 
de extrema importância, uma vez que a extrusão excessiva dos molares superiores é indesejada na correção da má oclusão de Classe II, $1^{\text {a divisão. }}$

Em relação à posição dos primeiros molares superiores no sentido ântero-posterior, avaliada pela grandeza $\underline{6}-\mathrm{FH}$, verificou-se uma distalização destes dentes no grupo tratado com o AEB conjugado $(-1,27 \mathrm{~mm})$ enquanto no grupo 3 (Bionator) houve suave mesialização $(0,10 \mathrm{~mm})$ e no grupo controle, como resultado do crescimento e desenvolvimento maxilar, o deslocamento para mesial foi maior $(0,92 \mathrm{~mm})$. No entanto, observou-se diferença estatisticamente significante apenas entre o grupo controle e o tratado com o AEB conjugado o que está de acordo com os estudos de Derringer ${ }^{20}$; Fotis et al. ${ }^{22}$; Henriques ${ }^{28}$; Maltagliati ${ }^{43}$; Martins ${ }^{46}$; Thurow ${ }^{58}$; Üner e Eroglu ${ }^{64}$. É importante ressaltar que no grupo 3 os molares apresentaram menor mesialização que no grupo controle, porém sem diferença estatística.

\section{Dentes inferiores}

O posicionamento dos incisivos inferiores, decorrente dos tratamentos instituídos evidenciou, efeitos distintos e estatisticamente significantes em relação ao grupo controle. No grupo tratado com o AEB conjugado, os incisivos lingualizaram e retruíram $\left(-2,22^{\circ}\right.$ e $\left.-0,22 \mathrm{~mm}\right)$ provavelmente devido à lingualização considerável dos homólogos superiores. Outro provável fator responsável pela verticalização dos incisivos inferiores no grupo 2 é a ação do lábio inferior sobre esses dentes, uma vez que o AEB conjugado promove a desoclusão, abrindo a mordida e aumentando a pressão labial nesta área. O grupo tratado com o Bionator apresentou uma inclinação para vestibular e protrusão $\left(4,25^{\circ}\right.$ e $\left.1,12 \mathrm{~mm}\right)$ maior do que o grupo controle $\left(0,33^{\circ}\right.$ e $\left.0,24 \mathrm{~mm}\right)$ com diferença estatisticamente significante. O grupo controle por sua vez apresentou discreta vestibularização e protrusão dos incisivos na base óssea. Os estudos de Caldwell, Hymas, Timm ${ }^{15}$; Henriques et al. ${ }^{30}$ e Maltaglia$\mathrm{ti}^{43}$ corroboram com estes resultados obtidos no grupo tratado com o AEB conjugado e somente a pesquisa de Martins $^{46}$ discorda destes efeitos mostrando que os incisivos inferiores não foram influenciados pelo tratamento. Concordando com os resultados referentes ao Bionator, vários autores $^{1,2,5,13,16,32,38,51,53,57,59}$ verificaram uma inclinação para vestibular e maior protrusão dos incisivos inferiores. De modo contrário, Bolmgren, Moshiri ${ }^{14}$; Wieslander e Lagerström ${ }^{68}$ demonstraram que os incisivos não sofreram alterações durante o tratamento com o ativador.

Quanto ao posicionamento vertical dos primeiros molares inferiores, os três grupos experimentaram um aumento da medida ( $\overline{6}$ - GoMe), denotando uma extrusão destes dentes, e apresentando diferença estatisticamente significante somente entre os grupos tratados $(1,78 \mathrm{~mm}$ - grupo 2 e $1,55 \mathrm{~mm}$ - grupo 3$)$ e o controle $(0,79 \mathrm{~mm})$. De forma similar, Almeida ; Almeida, Henriques, Ursi²; Almeida et al.5; Bishara, Ziaja ${ }^{13}$; Bolmgren, Moshiri ${ }^{14}$; Harvold, Vargervik ${ }^{26}$; Nelson, Harkness, Herbison $^{51}$; Tsamtsouris e Vedrenne ${ }^{59}$ afirmaram que o ativador/Bionator propiciou a extrusão dos dentes póstero-inferiores.

Analisando o deslocamento horizontal dos primeiros molares inferiores pela medida $\overline{6}$-FHP observou-se um comportamento similar nos três grupos, demonstrando mesialização destes dentes. No entanto, foram verificadas diferenças estatisticamente significantes entre os grupos tratados $(2,69 \mathrm{~mm}$ - grupo 2 e $3,27 \mathrm{~mm}$ - grupo 3$)$ e o controle $(1,05 \mathrm{~mm})$ sendo que neste último a mesialização foi menor. Nos grupos tratados esta mesialização, considerada como efeito positivo para a correção da relação molar, foi maior no grupo 2 cerca de $1,64 \mathrm{~mm}$ e no grupo 3 aproximadamente $2,22 \mathrm{~mm}$ em relação ao grupo não tratado. Este resultado corrobora com as pesquisas de Pancherz ${ }^{53}$; Schulhof, Engel ${ }^{55}$; Tsamtsouris e Vedrenne ${ }^{59}$.

Um dos mecanismos responsáveis pela correção da má oclusão de Classe II, $1^{a}$ divisão, fundamenta-se no princípio da erupção diferencial de Harvold que consiste na inibição da irrupção 
dos molares superiores no sentido ântero-inferior e promoção da extrusão e mesialização dos dentes póstero-inferiores. Esta assertiva refere-se aos aparelhos ortopédicos funcionais, no entanto ambos os aparelhos avaliados neste estudo produziram tais efeitos principalmente no arco inferior.

\section{CONSIDERAÇÕES FINAIS}

Contemporaneamente a Ortodontia cerca-se de inúmeros aparelhos ortopédicos para a correção da má oclusão de Classe II, $1^{\text {a }}$ divisão, no entanto ainda há controvérsia quanto aos efeitos dento-esqueléticos e tegumentares e em relação ao mecanismo de ação das diferentes abordagens terapêuticas. Os critérios de escolha do aparelho a ser instituído baseiam-se quase sempre em evidência clínica, científica e na morfologia craniofacial, e a definição do plano de tratamento se estabelece por meio das análises cefalométricas e facial.

É consenso entre os estudos que os dentes e as bases ósseas apicais podem ser efetivamente movimentados e reposicionados com aparelhos ortopédicos com a finalidade de corrigir, ou pelo menos amenizar, a discrepância dento-esquelética em uma fase de crescimento facial ativo. Quanto à alteração no perfil facial os trabalhos científicos mostram-se menos conclusivos aludindo resultados não tão promissores no restabelecimento da estética facial. Contudo ainda há dúvida se diferentes aparelhos ortopédicos produzem efeitos distintos sobre as estruturas ósseas, dentárias e tecidos moles.

$\mathrm{Na}$ tentativa de elucidar estes questionamentos executou-se esta pesquisa e a seguir serão apresentados o sumário dos efeitos suscitados pelas duas modalidades de tratamento ortopédico avaliadas.

A análise dos resultados mostrou que o tratamento da má oclusão de Classe II, $1^{a}$ divisão, com o AEB conjugado e com o Bionator resultou de efeitos específicos e inerentes a cada apare1ho. No entanto, ambos protocolos de tratamento propiciaram alterações esqueléticas, dentárias e tegumentares relevantes para a correção desta entidade. Esta afirmação torna-se evidente comparando-se os grupos experimentais ao grupo controle não tratado.

Os efeitos do crescimento e desenvolvimento craniofacial nos pacientes portadores de má oclusão de Classe II, $1^{\text {a }}$ divisão, que não receberam tratamento (grupo 1) mantiveram-se constantes perpetuando a má oclusão. Em relação às bases ósseas observou-se, neste grupo, uma suave porém não significante diminuição do grau de protrusão maxilar e mandibular. Assim, o relacionamento maxilo-mandibular manteve-se deficiente apresentando uma redução (ANB) de apenas $0,45^{\circ}$ não considerada, clinicamente e nem estatisticamente, significante. $\mathrm{O}$ padrão de crescimento apresentou pequenas alterações não relevantes como a diminuição do plano mandibular em relação à base do crânio (SN.GoGn), um suave aumento do plano palatino e um maior aumento das alturas facial ântero-inferior (AFAI) e posterior total (S-Go). Os incisivos superiores e inferiores inclinaram-se ainda mais para vestibular e protruíram nas respectivas bases ósseas, preservando o trespasse horizontal aumentado. Os molares superiores extruíram e mesializaram mais que nos grupos tratados, e com os molares inferiores ocorreu exatamente o contrário, menor extrusão e menor mesialização em relação aos outros grupos. Em relação ao perfil facial não se constatou alterações no ângulo nasolabial e nem na posição dos lábios superiores e inferiores.

O tratamento com o AEB conjugado proporcionou alterações esqueléticas tanto na maxila como na mandíbula e alterações dentárias. Houve restrição significativa do desenvolvimento maxilar para anterior, diminuindo as medidas SNA e Nperp-A e menor aumento do comprimento efetivo da maxila quando comparado ao grupo controle. A protrusão da mandíbula aumentou $\left(0,46^{\circ}\right)$ aproximadamente quatro vezes mais que no grupo controle $\left(-0,18^{\circ}\right)$ contudo os grupos não foram considerados estatisticamente diferentes. As dimensões mandibulares aumentaram sem 
denotar significância estatística, porém os efeitos deste aparelho no componente mandibular parecem contribuir clinicamente para a correção da má oclusão de Classe II, $1^{a}$ divisão, pois não dá para omitir que o deslocamento da mandíbula para anterior foi estimulado em cerca de $70 \%$ quando comparados os valores médios de Co-Gn do grupo controle $(3,23 \mathrm{~mm})$ com este grupo tratado $(5,29 \mathrm{~mm})$. A relação maxilo-mandibular foi significantemente melhorada. Não se observou efeitos estatisticamente significantes no padrão de crescimento craniofacial, entretanto, houve uma rotação do plano mandibular no sentido anti-horário o que é altamente favorável para a correção da má oclusão de Classe II, $1^{a}$ divisão. Os incisivos superiores inclinaram-se para lingual e foram retruídos nas bases apicais. Conseqüentemente os incisivos inferiores também inclinaram-se para lingual e retruíram acompanhando o movimento dos incisivos superiores. Os molares superiores distalizaram e os inferiores deslocaram-se para mesial contribuindo para a correção da relação molar. Constatou-se também um desenvolvimento vertical dos molares superiores e inferiores caracterizando extrusão destes dentes sem influência nas alturas faciais ântero-inferior e posterior. No perfil tegumentar as alterações restringiram-se ao posicionamento dos lábios que foram retruídos durante o tratamento.

Os efeitos produzidos pelo Bionator foram mais evidentes nos componentes mandibular e dentário. O grau de protrusão maxilar (SNA e Nperp-A) diminuiu suavemente e sem significância. A variação do comprimento efetivo da maxila (Co-A) apresentou o menor valor médio entre os três grupos: $0,81 \mathrm{~mm}, 1,72 \mathrm{~mm}$ (AEB conjugado) e $2,33 \mathrm{~mm}$ (controle) sugerindo uma restrição da maxila, no entanto, deve-se destacar que esta medida é influenciada pelo ponto condílio o qual desloca-se para anterior devido à remodelação da cavidade glenóide em conseqüência do avanço mandibular alusivo ao mecanismo de ação do Bionator, assim o efeito restritivo sobre a maxila é considerado uma interpretação inadequada. Um significante aumento da protrusão mandibular $\left(1,23^{\circ}\right)$ em relação aos dois outros grupos foi observado. As dimensões mandibulares aumentadas também foram afetadas pelo tratamento com o Bionator, no entanto assim como ocorreu no grupo tratado com o AEB conjugado, a diferença entre os grupos tratados e o grupo controle não foi estatisticamente significante. Porém ressalta-se que o valor médio da variação do comprimento efetivo da mandíbula com o Bionator $(4,15 \mathrm{~mm})$ foi $30 \%$ maior que no grupo controle $(3,23 \mathrm{~mm})$ e que não se pode desconsiderar esta alteração clinicamente significante. Conseqüentemente às alterações nas bases ósseas, ocorreu uma melhora significativa da relação maxilo-mandibular e da convexidade facial. O padrão de crescimento manteve-se estável assim como as alturas faciais que não mostraram alteração significante, não obstante os molares superiores e inferiores tenham extruído e mesializado. Os incisivos superiores inclinaram para lingual e retruíram, enquanto que os inferiores vestibularizaram e protruíram na base óssea, efeitos estes que contribuem sobremaneira para a correção da Classe II. O perfil facial mostrou poucas alterações restritas apenas à discreta retrusão do lábio superior.

Em resposta aos questionamentos destacados anteriormente verificou-se que diferentes abordagens terapêuticas podem corrigir uma mesma má oclusão produzindo efeitos distintos sobre as estruturas ósseas, os dentes e os tecidos moles. Comparando um aparelho ortopédico mecânico com um ortopédico funcional foi possível identificar algumas características distintas referentes ao modo de ação de cada aparelho. Ambos os protocolos de tratamento mostraram-se eficazes na correção da má oclusão de Classe II, $1^{\text {a }}$ divisão, promovendo grandes alterações dentárias e menores efeitos esqueléticos de acordo com outros estudos, como o de Bisahara e Ziaja ${ }^{13}$, que verificaram que a combinação dos efeitos dentoalveolares varia em torno de 60 a $70 \%$ e dos ortopédicos por volta de 30 a $40 \%$. 
Basicamente a diferença entre os efeitos esqueléticos promovidos pelos aparelhos avaliados residiu na restrição do componente maxilar pelo AEB conjugado, maior efeito no componente mandibular com o Bionator e controle vertical do crescimento facial obtido com o AEB conjugado. Em relação aos dentes superiores o AEB conjugado distalizou os molares, enquanto o Bionator praticamente não influenciou este posicionamento e ambos promoveram discreta extrusão destes dentes. Os incisivos superiores foram inclinados para lingual significantemente com ambos os aparelhos, o que pode ser considerado favorável no tratamento da Classe II, $1^{\text {a }}$ divisão, que exibe estes dentes moderados ou severamente inclinados para vestibular. Diante de uma moderada vestibularização dos incisivos superiores pode-se optar pelo Bionator enquanto em casos com severa inclinação para vestibular o $\mathrm{AEB}$ conjugado responde melhor, mas também promove retrusão, às vezes excessiva dos lábios superiores abrindo o ângulo nasolabial. Os incisivos inferiores vestibularizam com a terapia funcional do Bionator, se isto for desejável para o caso, ponto positivo para esta abordagem, do contrário pode-se indicar o AEB conjugado que inclina estes dentes para lingual. Os molares inferiores parecem ser igualmente afetados por ambos aparelhos que produzem extrusão e mesialização destes dentes.

As alterações suscitadas pelo AEB conjugado, neste estudo, contrariaram diversas pesquisas que relacionaram os efeitos deste aparelho somente ao componente maxilar. De acordo com Keeling et al. ${ }^{41}$; Wheeler et al. ${ }^{67}$ e You et al. ${ }^{69}$, um aparelho que promova desoclusão posterior associado a uma força extrabucal é capaz de restringir o crescimento anterior da maxila e liberar o crescimento mandibular produzindo efeitos semelhantes àqueles angariados com os aparelhos que avançam a mandíbula. Segundo a afirmação de Martins ${ }^{46}$ a ação de um AEB sobre a face média, isoladamente permite que a mandíbula complete seu crescimento normal contribuindo na correção da discrepância ântero-posterior, efeito este confirmado nesta pesquisa.

\section{CONCLUSÕES}

Em relação às alterações suscitadas pelo tratamento com os aparelhos estudados pode-se inferir:

\section{Componente maxilar}

O deslocamento anterior da maxila foi restringido significantemente pelo tratamento com o AEB conjugado. Diferentemente, o tratamento com o Bionator não propiciou alterações significantes no desenvolvimento maxilar.

\section{Componente mandibular}

O Bionator promoveu um aumento significante na protrusão mandibular, o AEB conjugado mostrou efeitos menos evidentes enquanto o grupo controle apresentou uma diminuição do grau de protrusão da mandíbula.

As dimensões mandibulares aumentaram sensivelmente nos grupos tratados, porém estes efeitos não foram considerados estatiscamente significantes. No entanto, cabe ressaltar que clinicamente os resultados podem ser significantes.

\section{Relação maxilo-mandibular}

Os aparelhos avaliados propiciaram uma melhora significante na relação maxilo-mandibular e na convexidade facial, com diminuição dos ângulos ANB e NAP.

\section{Relação vertical}

Nenhum dos aparelhos produziu alterações significantes no padrão de crescimento craniofacial. Nos grupos 1 e 2 verificou-se uma rotação do plano mandibular no sentido anti-horário. $\mathrm{O}$ posicionamento vertical da maxila (SN.PP) também não se alterou. A altura facial ântero-inferior (AFAI) e a altura facial posterior não mostraram alterações significantes, não se constatando os propagados efeitos deletérios dos aparelhos ortopédicos no aumento destas variáveis. 


\section{Componente dentoalveolar}

Ambos aparelhos provocaram inclinação para lingual e retrusão dos incisivos superiores, porém os efeitos do AEB conjugado foram significantemente mais intensos.

Os primeiros molares superiores não extruíram significantemente, mantendo estáveis suas posições no sentido vertical. No sentido ânteroposterior, verificou-se uma distalização destes dentes no grupo tratado com o AEB conjugado, enquanto nos grupos 3 (Bionator) e controle houve mesialização.
Os incisivos inferiores foram afetados de maneira distinta pelos aparelhos. No grupo tratado com o AEB conjugado, os incisivos lingualizaram e retruíram, enquanto o grupo tratado com o Bionator apresentou uma inclinação para vestibular e protrusão destes dentes.

Os primeiros molares inferiores apresentaram um deslocamento no sentido vertical (extrusão) e horizontal (mesialização) significantemente maior nos grupos tratados.

\title{
Treatment effects of maxillary splint and Bionator appliances in the treatment of Class II division 1 malocclusion
}

\begin{abstract}
The purpose of this investigation was to evaluate and compare the cephalometric changes of maxillary splint and bionator appliances on individuals with Class II, division 1 malocclusion. Lateral cephalograms were available for 90 patients of both sex, divided in three groups of 30 each one. The first group served as a control group, with initial mean age of 10.02 years. The second group was treated with maxillary splint appliance with initial mean age of 10.02 years. The group 3 was treated with Bionator appliance with initial mean age of 10.35 years. The lateral cephalometric headfilms were taken of each patient at the beginning and the end of treatment, in a total of 180 headfilms. The cephalometric variables were analyzed with statistical tests. The results showed that only maxillary splint influenced changes in forward growth of the maxilla and Bionator appliances provides a statistically significant increase in mandibular protrusion. However, it was observed that both appliances provides an increase in total mandibular and body length, with greater values in group 2, but these results do not showed statistically differences. This study indicated that both appliances provide an improvement in the maxillomandibular relationship, compared to the control group. In addition, there were no statistically significant differences in the craniofacial growth pattern among the three groups nor in the facial heights. It was observed that both appliances produced lingual inclination and retrusion of the upper incisors. Maxillary splint provided lingual tipping of the lower incisors while Bionator produced labial tipping and protrusion of these teeth. The lower molars showed a greater vertical development and extrusion in experimental groups. The maxillary splint produced distal movement of the first upper molars and bionator showed mesial inclination.
\end{abstract}

Key words: Maxillary splint and Bionator appliances. Class II, division 1. Orthopedics.

\section{REFERÊNCIAS}

1. ALMEIDA, M. R. Avaliação cefalométrica comparativa da interceptação da má oclusão de Classe II, $1^{\text {a }}$ divisão utilizando - aparelho de Fränkel e o Bionator de Balters. 2000. $241 \mathrm{f}$. Tese (Doutorado) - Faculdade de Odontologia de Bauru, Universidade de São Paulo, Bauru, 2000.

2. ALMEIDA, M. R.; HENRIQUES, J. F. C.; URSI, W. J. S. Comparative study of the Fränkel (FR-2) and bionator appliances in the treatment of Class II malocclusion. Am J Orthod Dentofacial Orthop, St. Louis, v. 121, no. 5, p. 458-466, May 2002.
3. ALMEIDA, M. R. et al. Estudo cefalométrico comparativo, da ação de dois tipos de aparelhos ortopédicos, sobre as estruturas dentoesqueléticas e tegumentares de jovens de ambos os sexos com más oclusões de Classe II, $1^{\text {a }}$ divisão. Ortodontia, São Paulo, v. 31, n. 2, p. 32-52, maio./ago. 1998.

4. ALMEIDA, M. R. et al. O tratamento da Classe II, divisão 1 com o uso do AEB conjugado e aparelho fixo. R Clin Ortodon Dental Press, Maringá, v. 1, n. 3, p. 63-71, jun./jul. 2002.

5. ALMEIDA, M. R. et al. Treatment effects produced by the Bionator appliance. Comparision with an untreated Class II sample. Eur J Orthod, London, v. 26, n.1, p. 65-72, 2004. 
6. ALMEIDA, R. R. et al. Utilização do AEB conjugado na interceptação da má-oclusão de Classe II, $1^{\text {a }}$ divisão. Rev APCD, São Paulo, v. 56, n. 4, p. 308-312, jul./ago. 2002.

7. ALTUNA, G.; NIEGEL, S. Bionators in Class II treatment. J Clin Orthod, Boulder, v. 19, no. 3, p. 185-191, Mar. 1985.

8. ANGLE, E. H. Classification of malocclusion. Dent Cosmos, Philadelphia, v. 41, no. 3, p. 248-264, 350-357, Mar. 1899.

9. BASS, N. M. Dento-facial orthopaedics in the correction of Class II malocclusion. Br J Orthod, London, v. 9, no. 1, p. 3-31, Jan. 1982.

10. BASS, N. M. Orthopedic coordination of dentofacial development in skeletal Class II malocclusion in conjuction with edgewise therapy. Part I. Am J Orthod, St. Louis, v. 84, no. 5, p. 361-383, Nov. 1983.

11. BASS, N. M. Orthopedic coordination of dentofacial development in skeletal Class II malocclusion in conjuction with edgewise therapy. Part II. Am J Orthod, St. Louis, v. 84, no. 6, p. 466-490, Dec. 1983

12. BAUMRIND, S.; FRANTZ, R. C. The reliability of head film measurements. 1. Landmark identification. Am J Orthod, St. Louis, v. 60, no. 2, p. 111-127, Aug. 1971.

13. BISHARA, S. E.; ZIAJA, R. R. Functional appliances: a review. Am J Orthod Dentofacial Orthop, St. Louis, v. 95, no. 3 p. 250-258, Mar. 1989

14. BOLMGREN, G. A.; MOSHIRI, F. Bionator treatment in Class II, division 1. Angle Orthod, Appleton, v. 56, no. 3, p.255-262, July 1986.

15. CALDWELL, S. F.; HYMAS, A.; TIMM, T. A. Maxillary traction splint: a cephalometric evaluation. Am J Orthod, St. Louis, v. 85, no. 5, p. 376-384, May 1984.

16. CHANG, $H$. et al. Effects of activator treatment on Class II, division 1 malocclusion. J Clin Orthod, Boulder, v. 23, no. 8, p. 560-563, Aug. 1989.

17. CHEN, J. Y.; WILL, L. A.; NIEDERMAN, R. Analysis of efficacy of functional appliances on mandibular growth. Am J Orthod Dentofacial Orthop, St. Louis, v. 122, no. 5, p. 470-476, Nov. 2002.

18. COURTNEY, M.; HARKNESS, M.; HERBISON, P. Maxillary and cranial base changes during treatment with functional appliances. Am J Orthod Dentofacial Orthop, St. Louis, v. 109, no. 6 , p. 616-624, June 1996.

19. DE VINCENZO, J. P. Changes in mandibular lenght before, during, and after successful orthopedic correction of Class II malocclusions, using a functional appliance. Am J Orthod Dentofacial Orthop, St. Louis, v. 99, no. 3, p. 241-257, Mar. 1991.

20. DERRINGER, K. A cephalometric study to compare the effects of cervical traction and Andresen therapy in the treatment of Class II division 1 malocclusion. Part 1-Skeletal changes. Br J Orthod, London, v. 17, no. 1, p. 33-46, Feb. 1990

21. FALTIN JUNIOR, K. et. al. Long-term effectiveness and treatment timing for bionator therapy. Angle Orthod, Appleton v. 73 , no. 3, p. 221-230, June 2003.

22. FOTIS, V. et al. Vertical control as an important ingredient in the treatment of severe sagital discrepancies. Am J Orthod St. Louis, v. 86, no. 3, p. 224-232, Sept. 1984.

23. FREITAS, M.R. et. al. Prevalência das más oclusões em pacientes inscritos para tratamento ortodôntico na Faculdade de Odontologia de Bauru-USP. Rev Fac Odontol Bauru, Bauru, v.10, n. 3 p. 164-169, 2002.

24. FREUNTHALLER, P. Cephalometric observations in Class II, division I malocclusions treated with the activator. Angle Orthod Appleton, v. 37, no. 1, p. 18-25, Jan. 1967.

25. GHAFARI, J.: KING, G. J.: TULLOCH, J. F.C. Early treatment of Class II, division 1 malocclusion-comparison of alternative treatment modalities. Clin Orthod Res, Chicago, v. 1, no. 2 , p. 107-117, Nov. 1998.

26. HARVOLD, E. P.; VARGERVIK, K. Morphogenetic response to activator treatment. Am J Orthod, St. Louis, v. 60, no. 5 , p. 478-490, Nov. 1971.

27. HASHIM, H. A. Analysis of activator treatment changes. Austr Orthod J, Brisbane, v. 12, no. 2, p. 100-104, Oct. 1991
28. HENRIQUES, J. F. C. Estudo cefalométrico comparativo, de três tipos de ancoragem extrabucal, sobre as estruturas dentoesqueléticas, em pacientes com Classe II, 1 $^{\text {a }}$ divisão. 1993. 166 f. Tese (Livre Docência) - Faculdade de Odontologia de Bauru, Unversidade de São Paulo, Bauru, 1993.

29. HENRIQUES, J. F. C.; FREITAS, M. R.; SANTOS PINTO, C. C. M. Correção de uma má oclusão de classe II, divisão 1, com protrusão maxilar, utilizando o arco facial conjugado a um aparelho removível (AEB conjugado). Ortodontia, São Paulo, v. 24, n. 3, p. 14-18, set./dez. 1991.

30. HENRIQUES, J. F. C. et al. Modified maxillary splint for Class II, division 1 treatment. J Clin Orthod, Boulder, v. 25, no. 4, p. 239-245, Apr. 1991.

31. HENRIQUES, J. F. C. et al. Utilização do aparelho removível conjugado à ancoragem extrabucal para a correção da má oclusão de Classe II, $1^{\text {a }}$ divisão, com sobremordida profunda. R Dental Press Ortodon Ortop Facial, Maringá, v. 2, n. 2, p. 12-18, mar./abr. 1997

32. HENRIQUES, J. F. C. et al. Tratamento da má oclusão de Classe II, $1^{\text {a }}$ divisão com retrusão mandibular utilizando o Bionator previamente à aparelhagem fixa: relato de um caso clínico. Ortodontia, São Paulo, v. 30, n. 3, p. 74-79, set./dez. 1997.

33. HENRIQUES, J. F. C. et al. Estudo longitudinal das características da má oclusão de Classe II, $1^{\text {a }}$ divisão sem tratamento, em jovens brasileiros, leucodermas, por um período médio de 3 anos. R Dental Press Ortodon Ortop Facial, Maringá, v. 3, n. 3, p. 52-66, maio/jun. 1998

34. HOUSTON, W. J. B. The analysis of errors in orthodontic measurements. Am J Orthod Dentofacial Orthop, St. Louis, v. 83, no. 5 , p. 382-390, May 1983.

35. ILLING, H. M.; MORRIS, D. O.; LEE, R. T. A prospective evaluation of bass, bionator and twin block appliances. Part I - the hard tissues. Eur J Orthod, London, v. 20, no. 5, p. 501-516, Oct. 1998.

36. JACOBS, T.; SAWAENGKIT, P. National Institute of Dental and Craniofacial Research efficacy trials of bionator Class II treatment: a review. Angle Orthod, Appleton, v. 72, no. 6, p. 571-575, Dec. 2002

37. JAKOBSSON, S. O.; PAULIN, G. The influence of activator treatment on skeletal growth in Angle Class II:1 cases. A roentgenocephalometric study. Eur J Orthod, London, v. 12, no. 2, p. 174-184, May 1990.

38. JANSON, I. A. A cephalometric study of the efficiency of the bionator. Trans Eur Orthod Soc, London, v. 28, p. 283-298, 1977.

39. JANSON, I. R.; NOACHTAR, R. Functional appliance therapy with the bionator. Semin Orthod, Philadelphia, v. 4, no. 1, p. 33-45, 1998.

40. JOFFE, L.; JACOBSON, A. The maxillary orthopedic splint. Am J Orthod, St. Louis, v. 75, no. 1, p. 54-69, Jan. 1979.

41. KEELING, S. D. et al. Anteroposterior skeletal and dental changes after early Class II treatment with bionators and headgear. Am J Orthod Dentofacial Orthop, St. Louis, v. 113, no. 1, p. 40-50, Jan. 1998.

42. LANGE, D. W. et al. Changes in soft tissue profile following treatment with the bionator. Angle Orthod, Appleton, v. 65, no. 6, p. 423-430, Mar. 1995.

43. MALTAGLIATI, L. A. Estudo comparativo das alterações dentoesqueléticas da má oclusão de Classe II, 1a divisão de Angle, nos jovens sem tratamento e nos submetidos a dois tipos de aparelho ortodôntico. 1997. 226 f. Dissertação (Mestrado) - Faculdade de Odontologia de Bauru, Universidade de São Paulo, Bauru, 1997.

44. MAMANDRAS, A. H.; ALLEN, L. P. Mandibular response to orthodontic treatment with the bionator appliance. Am J Orthod Dentofacial Orthop, St. Louis, v. 97, no. 2, p. 113-120, Feb. 1990.

45. MARTINS, D. R. et al. Atlas de desenvolvimento craniofacial. São Paulo: Ed. Santos, 1998.

46. MARTINS, J. C. R. Avaliação cefalométrica comparativa dos resultados da interceptação da má oclusão de Classe II, divisão $1^{\text {a }}$ de Angle, efetuados com o aparelho extrabucal ou com o bionator. 1997. 333 f. Tese (Livre-docência) - Faculdade de Odontologia de Araraquara, Universidade Estadual Paulista, Araraquara, 1997 
47. McNAMARA JR. J. A. Components of Class II malocclusion in children 8-10 years of age. Angle Orthod, Appleton, v. 51, no. 3, p. 177-202, July 1981.

48. MEACH, C. L. A cephalometric comparison of bony profile changes in Class II, Division 1 patients treated with extraoral force and functional jaw orthopedics. Am J Orthod, St. Louis, v. 52 , no. 5 , p. 353-370, May 1966

49. MILLS, J. R. E. The effect of functional appliances on the skeletal pattern. Br J Orthod, London, v. 18, no. 4, p. 267-275, Nov.1991.

50. MORRIS, D. O.; ILLING, H. M.; LEE, R. T. A prospective evaluation of bass, Bionator and Twin Block appliances. Eur J Orthod, London, v. 20, no. 6, p. 663-684, Dec. 1998.

51. NELSON, C.; HARKNESS, M.; HERBISON, P. Mandibular changes during functional appliance treatment. Am J Orthod Dentofacial Orthop, St. Louis, v. 104, no. 2, p. 153-161, Aug. 1993.

52. OP HEIJ, D. G.; CALLAERT, H.; OPDEBEECK, H. M. The effect of the amount of protrusion built into the bionator on condylar growth and displacement: a clinical study. Am J Orthod Dentofacial Orthop, St. Louis, v. 95, no. 5, p. 401-409, May 1989.

53. PANCHERZ, H. A cephalometric analysis of skeletal and dental changes contributing to Class II correction in activator treatment. Am J Orthod Dentofacial Orthop, St. Louis, v. 85, no. 2, p. 125-134, Feb. 1984.

54. PFEIFFER, J. P.; GROBÉTY, D. The Class II malocclusion: differential diagnosis and clinical application of activators, extraoral traction and fixed appliances. Am J Orthod, St. Louis, v. 68, no. 5, p. 499-544, Nov. 1975.

55. SCHULHOF, R. J.; ENGEL, G. A. Results of Class II functional appliance treatment. J Clin Orthod, Boulder, v. 16, no. 9, p. 587-599, Sept. 1982.

56. SEÇKIN, O.; SURUCU, R. Treatment of class II, division 1 cases with a maxillary traction splint. Quintessence, Berlin, v. 21, no. 3, p. 209-215, 1990

57. THÜER, U.; INGERVALL, B.; BÜRGIN, W. Does the mandible alter its functional position during activator treatment? Am J Orthod Dentofacial Orthop, St. Louis, v. 96, no. 6, p. 477-484, Dec. 1989

58. THUROW, R.C. Craniomaxillary orthopedic correction with the en masse dental control. Am J Orthod, St. Louis, v. 68, no. 6, p. 601-624, Dec. 1975 .
59. TSAMTSOURIS, A. VEDRENNE, D. The use of the bionator appliance in the treatment of Class II, division 1 malocclusion in the late mixed dentition. J Pedod, Birmingham, v. 8, no. 78, p. 78-100, 1983

60. TULLEY, W. J. The scope and limitations of treatment with the activator. Am J Orthod, St. Louis, v. 61, no. 6, p. 562-577, June 1972.

61. TULLOCH, J. F.; PROFFIT, W. R.; PHILLIPS, C. Influences on the outcome of early treatment for Class II malocclusion. Am J Orthod Dentofacial Orthop, St. Louis, v. 111, no. 5, p. 533-542, May 1997.

62. TULLOCH, J. F.; PHILLIPS, C.; PROFFIT, W. R. Benefit of early Class II treatment: progress report of a two-phase randomized clinical trial. Am J Orthod Dentofacial Orthop, St. Louis, v. 113 , no. 1 , p. $62-72$, Jan. 1998.

63. TULLOCH, J. F. et al. The effect of early intervention on skeletal pattern in Class II malocclusion: a randomized clinical trial. Am J Orthod Dentofacial Orthop, St. Louis, v. 111, no. 4, p. 391-399, Apr. 1997.

64. ÜNER, O.; EROGLU, E. Y. Effects of a modified maxillary or thopaedic splint: a cephalometric evaluation. Eur J Orthod London, v. 18, no. 3, p. 269-286, June 1996.

65. URSI, W. J. S. Alteração clínica da face em crescimento: uma comparação cefalométrica entre os aparelhos extrabucal cervical, Fränkel (FR-2) e Herbst no tratamento das oclusões de Classe II, primeira divisão de Angle. 1993. 168 f. Tese (Doutorado) - Faculdade de Odontologia de Bauru, Universidade de São Paulo, Bauru, 1993.

66. VARGERVIK, K.; HARVOLD, E. P. Response to activator treatment in Class II malocclusions. Am J Orthod, St. Louis, v. 88 no. 3, p. 242-251, Sept. 1985.

67. WHEELER, T. T. et al. Effectiveness of early treatment of Class II malocclusion. Am J Orthod Dentofacial Orthop, St. Louis, 121, no. 1, p. 9-17, Jan. 2002

68. WIESLANDER, L.; LAGERSTRÖM, L. The effect of activator treatment on Class II malocclusions. Am J Orthod, St. Louis, v. 75 no. 1, p. 20-26, Jan. 1979

69. YOU, Z. H. et al. Dentoalveolar changes related to mandibular forward growth in untreated Class II persons. Am J Orthod Dentofacial Orthop, St. Louis, v. 120, no. 6, p. 598-607, Dec. 2001
Endereço para correspondência

Renata Rodrigues de Almeida-Pedrin

Rua Saint Martin, 35-28

CEP. 17.012-433 - Bauru/SP

E-mail: renatinhaalmeida@uol.com.br 